REVISTA CHILENA DE LITERATURA

Abril 2010, Número 76, 105 - 127

\title{
EXILIO E INSILIO: REPRESENTACIONES POLÍTICAS Y SUJETOS ESCINDIDOS EN LA POESÍA CHILENA DE LOS SETENTA*
}

\author{
Naín Nómez \\ Universidad de Santiago de Chile \\ nain.nomez@usach.cl
}

RESUMEN / ABSTRACT

Este artículo hace un recuento y un análisis de la poesía chilena que se produce dentro y fuera de Chile en los años setenta, con especial énfasis en la concepción del exilio y el insilio. Además de focalizarse en las problemáticas "exilio-insilio", su desarrollo y posterior integración, este trabajo analiza fundamentalmente las relaciones que se producen entre los poetas y su entorno a través de sus representaciones subjetivas en diferentes situaciones y lugares, especialmente urbanos. Tanto las ciudades del interior como las ciudades del exilio adquieren connotaciones represivas que inciden en las problemáticas de un sujeto escindido en los poemas.

Palabras Clave: poesía chilena, dictadura, exilio, insilio, ciudad.

This article is an inventory and analysis of Chilean Poetry in the seventies, written in Chile and abroad, emphasizing the "exilio" and "insilio" concept. Apart from focusing on the "exilio-insilio" problem, its development and subsequent integration, this work analyzes the relationships between poets and their enviroment by means of subjective representations in different situations and places (especially urban). The cities of Chile, as well as foreign cities in the countries of exile, acquire repressive connotations, which influence the problems of the divided subject in this poetry.

KEY WORDS: Chilean Poetry, Dictatorship, Exile, “Insilio”, City.

* Este articulo forma parte del proyecto Fondecyt No 1085255 (2008-2010) del cual soy co-investigador. 


\section{PRESENTACIÓN}

Lo primero que habría que señalar es que no creemos que el campo cultural (el campo literario-poético en este caso), se desarrolle solo en base a la producción de las vanguardias o de los escritores "novísimos". Para existir, el campo requiere de un escenario amplio, conformado por las distintas posiciones (vanguardias, tradición, oficialismo, clásicos, novísimos, sobrevivientes, etc.) y donde cada una de ellas tiene un sentido, le da sentido a las diferentes perspectivas artísticas que dialogan, discuten, combaten y se transforman ellas mismas en un movimiento constante (Bourdieu 79-261). Pertenecer al canon o "pasar a la historia" forma parte del proceso cultural a través del cual las obras se academizan o se neutralizan; en este sentido, toda vanguardia pasa a ocupar el lugar del canon aunque siempre hay excepciones que persisten en ser vanguardia en el tiempo. El envejecimiento de los autores se engendra en el combate entre aquellos que hicieron época, los que luchan por seguir existiendo y aquellos que no pueden hacer época sin remitir al pasado a los autores, que quieren detener el tiempo y eternizar su estado presente. Para "hacer época" es necesario hacer existir una "nueva posición”, en vanguardia, más allá de las posiciones establecidas. Pero en el movimiento permanente que es la relación entre, por un lado, los cambios contextuales (históricos, sociales, culturales) locales, regionales, nacionales e internacionales y por un segundo lado, las posiciones de los productores, lectores, críticos, medios de comunicación y otros actores en el campo, las vanguardias se hacen tradición y ciertas posiciones que en un momento del estado del arte se presentan como tradicionales, cambian de posición y pueden llegar de nuevo a ser vistos como vanguardia (a partir de un trabajo sobre los significantes que hasta ese momento permanecía invisibilizado o por la resignificación de discursos considerados tradicionales, por ejemplo en el caso de Marta Brunet, o de Gabriela Mistral, Carlos Pezoa Véliz y Pablo de Rokha, en la poesía chilena).

En un artículo de 1998, Javier Campos cuestionaba la mirada de los poetas del 60 en torno al problema tecnológico y la sociedad de consumo, problema que ya estaba vigente en los poetas latinoamericanos del período (78). Desde luego es el caso de poetas como Ernesto Cardenal, Carlos Germán Belli, Saul Yurkievich en los cincuenta y José Carlos Becerra, Pablo Guevara, José Luis Vega, entre otros, en los sesenta. Su planteamiento es que el único poeta que lo hace en Chile es Gonzalo Millán ya en Relación personal (cita el poema "Y tu piel me es doblemente extraña" y luego el poema "El automóvil"). 
Estos efectos del proceso de modernización del nuevo capitalismo que ya se vislumbra en los 60 parecieran ligarse a una poesía política mediatizada, donde el blanco no es directamente la opresión, la sociedad capitalista tradicional o la lucha de clases, sino los efectos nocivos que las nuevas relaciones de producción y consumo traen al mundo occidental.

\section{LA POESÍA EN EL INTERIOR DEL PAÍS: EL INSILIO}

Es importante señalar que si bien el Golpe de Estado con su represión, sus torturas, sus desaparecidos, sus encarcelamientos y sus expulsiones, propugna una literatura abiertamente testimonial, política y a veces incluso hasta subversiva, el concepto de poesía política puede aplicarse a una vasta gama de discursos literarios que van desde el panfleto o el libelo abiertamente provocador hasta las formas más subrepticias, como las enunciadas por Campos más arriba, y que a su juicio constituyen una forma minoritaria de expresión en la lírica nacional del período anterior a la dictadura. Es este amplio abanico de textualidades el que nos interesa aquí introducir de una manera somera y general, cuando nos referimos a la poesía política, la cual a veces también se toca con la neovanguardista o con formas recicladas de posturas estéticas entrecruzadas como es la poesía intimista, la poesía lárica, la poesía epigramática o la antipoesía, por citar solo algunas.

Un elemento central de este tipo de poesía es el sentido de pérdida. Creo que ese sentido de pérdida existió desde mucho antes y la poesía anterior al 73 es rica en matices de este tipo. En la antología hecha por Jaime Quezada y publicada en julio de 73 podemos encontrar varios ejemplos. Omar Lara escribe: "hablamos con seres de otras edades / y adivinamos el porvenir/ encontramos una aguja en un pajar/ y la perdemos oh dios" ("Poderío" 15). Y casi como premonición si no fuera por el título, el siguiente texto: "renacerán de sus cenizas como frutos/ de una extraña ecuación, es posible que lloren,/...Pero un día de lluvia/lavará/ lo que pudo dejar ese fantasma" ("La pareja"19). Y a propósito de la visión sobre el consumo y la tecnología que Campos echa de menos en los poetas de los sesenta, este texto de Hernán Lavín Cerda:

Ya no vas a seguir ahorrando/ en el Banco del Estado que ayuda a vivir/mejor a todos los chilenos./ Ya no vas a seguir invirtiendo /en los Bonos reajustables CAR./ Dejarás de ser el hombre de acción/ que viste con Contilén, la fibra que viste bien....Nunca más volverás 
a ser el hombre del primer plano, el hombre de Bellavista-Tomé (Quezada, "Ya no eres el hombre" 35).

A propósito de la caída del tiempo y la petrificación del yo, Waldo Rojas escribe: "Han caído los años y su chapuceo de peces./Seca o derruida la fuente del Cetrero,/y nosotros sin hablarnos./Como sucede hasta este mismo día" (Quezada, "Proustiana" 93). En Rojas, las premoniciones, aunque ambiguas, pululan en los poemas con una carga angustiante y una atmósfera que preanuncia desastres: "ese reguero de huellas de ratas/camino del magnolio del jardín" (Quezada, "Fotografía al magnesio" 94); "En las altas murallas de ladrillos/ decrecen sombras y musgosidades"...”está la hiedra irguiendo sordas reptaciones"..."los días son sombras que se anudan a un vástago inmóvil" (Quezada, "No hay enemigo eterno" 96); "Ocultan bajo la tierra lo infamante"; "saltan las aldabas del salón aterrador,/ astillado el mármol del tieso cortinaje, y al conjuro del hierro/ craqueteado/ astíllase asimismo toda cosa de madera" (Quezada, "El grito" 99). O la premonitoria alusión de "Lobos y ovejas" de Manuel Silva Acevedo: "Por qué si soy oveja/ deploro mi ovina mansedumbre/ Por qué maldigo mi pacífica cabeza/ vuelta hacia el sol/ Por qué deseo ahogarme/ en la sangre de mis brutas hermanas/ apacentadas" (Quezada 117).

Ya en el 68, La Escuela de Santiago había mostrado en sus textos algunos signos de la amenaza ominosa que se cernía sobre el sujeto enclaustrado en una urbe cada vez más alienante y donde la represión es parte de esa amenaza. Jorge Etcheverry describe en "X":

La ciudad oyó las caracolas: las plantas situadas a los pies de la cordillera han interrumpido el suministro de energía. Las sirenas en vano estocan el pecho de la noche. La cordillera nos impide huir a campo traviesa. A campo traviesa, y por lo tanto permanecemos fumando en la oscuridad eléctrica y el alba no llega. Las caracolas responso con el viento que baja de los astros... (Orfeo 222).

Y en Naín Nómez:

Yo era un ciudadano / con los derechos y deberes usuales...Ni mejor ni peor que lo demás...Pero sucedió/ aunque yo tenía un buen puesto en el Banco/ (siempre difícil de conseguir)/ y había tanta confianza alrededor/ como para que todo continuara detenido.... Nos rodearon./ Las luces del tránsito atornillaron todo el horizonte/ se fueron cabalgando hasta la noche/ atraparon la luna/ (y las bocinas ululando 
impacientes)./ Los muros nos desbordaron./ ningún ciudadano pudo arrastrarse más allá del crepúsculo" (Antología, "Fiseipolys" 209).

Así es como el sentido de pérdida, de angustia ante lo impredecible, de atmósferas irrespirables, está entrecruzado en los poemas con una vaga premonición utópica que nunca termina de concretarse, como ocurría con los poetas vanguardistas inmersos en el proyecto de la transformación social y ética (léase Neruda, de Rokha). En el caso chileno, si bien los años sesenta fueron representados con una estética politizada, esta se matizó permanentemente con un rescate de las emociones individuales (el amor, la vida cotidiana, las relaciones humanas), el retorno a una naturaleza humanizada y originaria o la visión angustiada frente a la existencia transitoria, entre otras representaciones alternativas. Existía una fuerte antipatía por Neruda y en parte eso repercutía en la crítica a la poesía comprometida más directamente. Militantes o simpatizantes de proyectos de izquierda o revolucionarios, los poetas no establecían una continuidad necesaria entre revolución política y militancia estética, sino más bien intentaban escribir una poesía personal arraigada en una visión de mundo específica. En esa visión, la ruina humana pasa a tener un papel central frente a una naturaleza regenerada. La ruina alcanza a veces a la cultura, pero no siempre. En este sentido, hay una continuidad con los poetas de los cincuenta (Teillier, Barquero, Uribe, Parra, Alcalde, Rubio, Arteche), que recuperan bajo distintos aspectos una naturaleza humanizada para establecer su crítica sobre el nuevo mundo urbano trasunto de una modernidad incompleta que se ve como posibilidad, pero también como amenaza y causante de un corte radical con una naturaleza hacia la cual el poeta se acercó históricamente con benevolencia aunque también con aprensión.

Es por ello que el movimiento de la producción chilena no se pierde ni se corta, sino que solo se transforma en el proceso de los primeros años de dictadura, cuando el reordenamiento de la institucionalización autoritaria obligaba a los poetas del interior del país a la autocensura, la escritura panfletaria, la protesta comprometida y la búsqueda de nuevas fórmulas escriturales para dar cuenta de una realidad fragmentada. Este período, el más oscuro de la fase terrorista del sistema, establece un ordenamiento ejemplarizador en que la razón de Estado está por sobre los individuos y el terror tiene como único objetivo derrotar el Mal: ejecuciones, campos de concentración, torturas, desaparecidos y exilio. 
A partir de la dictadura, las posiciones frente a lo político se radicalizan. En este sentido, es bueno establecer algunas diferencias entre los poetas que de una u otra manera desarrollan una representación más directa de la circunstancia vital que viven o de la coyuntura histórica que representan en los poemas, de otros que utilizan un lenguaje mas indirecto, distanciado, ambiguo, o que buscan privilegiar la comunicación con un lector activo antes que la forma tautológica del mensaje político directo. Por ejemplo, el tópico de la muerte que obsesiona la poesía de Oscar Hahn se hace más concreto en muchos poemas posteriores a 1973, aunque su caso no sea el más indicado para expresar estos cambios. Pero un poema como "Año viejo 1973", publicado primero en forma anónima, expresa este acercamiento a la coyuntura: "Se terminó este año cabrón. Se fue a la cresta...Con sus terrores y llantos y entierros a cuestas/ y los cuatro jinetes del Apocalipsis" (Lara y Epple 21). O por citar otro poema que tiene un epígrafe fechado en septiembre de 1973: "Hay un muerto flotando en este río/ y hay otro muerto más flotando aquí" (Hahn, Antología virtual, "Un ahogado pensativo a veces desciende" 63). Dentro de Chile, hay una poesía de denuncia como el "Somos cinco mil" de Víctor Jara y una serie de poetas anónimos que hacen circular sus poemas de mano en mano. Esta es la poesía que más se acerca a la idea de "poesía comprometida" o "poesía política", en el sentido un tanto despectivo que le dan los que apuestan por un discurso más vanguardista. Sin embargo, se podría decir que aunque prolifera en forma profusa, no es la única, ni probablemente la mayoritaria. Dentro de ella podría incluirse a Aristóteles España con su libro Equilibrio e incomunicaciones, escrito en el campo de concentración de la Isla Dawson entre septiembre de 1973 y julio de 1974 y publicado más tarde como Dawson (1985): “Qué será de Chile a esta hora?/ Vemos el sol mañana?/ se escuchan voces de mando y entramos en un callejón esquizofrénico...Las ventanas de la vida se abren o cierran" ("Llegada" 15). Pero no se trata de un texto panfletario ni de un simple testimonio de prisionero. El sujeto del poema no solo pregunta, se queja, se angustia, se enrabia con la situación imperante, sino que también cuestiona, proyecta, denuncia y, por sobre todo, describe como un cronista que se acongoja, aunque sigue reflexionando, sin ceder a la pura emoción: "hago preguntas, anoto, observo todo lo que ocurre" ("Balas y reencuentros" 63). O como añade el sujeto de "Infierno y soledad": "Han pasado ya trescientas horas/ -más o menos-/ y algunos leves nubarrones,/ estornudos, azotes,/ los Agentes de Seguridad no nos dejan dormir,/ interrogan y torturan/ a la luz de la luna y de las linternas" (17). Lo mismo podría decirse de un poema 
de Ana María Vergara titulado "Que digiera bien señora”: “¿Está 1lena/su cacerola/ ahora, señora?/ ¿De qué?/ ¿De carne?/ ¿De hígado?/ ¿De lengua? / ¿De qué/ está llena/ cree Ud./ señora/ su cacerola?” (Lara y Epple 19-20). $\mathrm{Al}$ intensificar la pregunta y relevar el símbolo/metonimia de la cacerola llena en oposición a la "marcha de las cacerolas vacías" realizada por las mujeres de la burguesía en 1972, muestra a la vez el síntoma y el efecto de la dictadura. La simple reiteración de la pregunta marcada por la ironización, al ser contextualizada se convierte en un signo del estado de cosas con una carga política profunda. Del mismo tenor es Carta de prisionero de Floridor Pérez, publicado definitivamente en 1984, pero que incluye poemas escritos a fines de 1973 en la Isla Quiriquina donde el poeta estuvo recluido. Más que la ironía es aquí el humor el que sirve de puerta de escape al temor y la angustia, aunque también sirve como técnica corrosiva frente a la situación degradada:

Todavía me pregunto por qué tú/ -por qué tú y no yo-/ por qué tú que alzabas gordos sacos/ y cargabas camiones cargados como sacos/ $\mathrm{y}$ te tiraron muerto junto a mí/ con tu poncho de pobre/ como un carnero blanco degollado/ por qué tú, por la cresta, y no yo/ que ni me puedo el diccionario de la Real Academia en una mano?" ("In Memorian" 39).

$\mathrm{O}$ en este otro texto donde invoca la censura que rige en el país: "Pienso pedir un minuto de silencio/ pero tardo horas y horas/ en sacar la voz" ("Septiembre 23/73", 13), que remite tanto a la censura como a la autocensura, a la denuncia como al trasfondo de la represión en una ciudad despoblada: "minuto de silencio" por los muertos versus "sacar la voz" por los vivos, antinomia irreductible.

En otro tono, el sujeto testimonial de José Ángel Cuevas se sitúa desde la nostalgia y la pérdida para dar cuenta de la realidad desmantelada: "de pronto, se encendieron las luces,/ se desarmó el tablado, con sus ternos de anchas solapas/ y camiones rugiendo. Se desarmó.../Empezó el Estado de Emergencia.../Mis amigos no están, murieron, se extraviaron, engordaron, y uno que otro, que anda por ahí,/ está muy ocupado" (Adiós muchedumbres, "Los últimos días de la década sesenta" 18). Como muchos de los poetas de ese período más atentos a las prácticas sociales que al reconocimiento literario, pero también por las imposibilidades editoriales y la censura durante el período dictatorial, Cuevas publica tardíamente y en forma artesanal algunos de sus libros, recopilados en 1989 bajo el título de Adiós 
muchedumbres. Estos textos serán Efectos personales y dominios públicos (1979), Introducción a Santiago (1982), Contravidas (1983), Canciones rock para chilenos (1987) y Cánticos amorosos y patrióticos (1988). El sujeto de los poemas de Cuevas se desenvuelve entre dos tiempos, entre los cuales es un testigo cuyas esperanzas pasadas se han convertido en desencanto y felicidad. El discurso es crítico, desgarrado, irónico, con un estilo conversacional y narrativo que busca aproximarse al testimonio y la memoria. Si bien su poesía puede situarse en el ámbito de una nostalgia desgarrada entre las utopías del pasado y la degradación del presente, en los textos no hay complacencia, ni protesta panfletaria ni utopía social. Su poesía es anti vanguardista, pero no retrógrada. La instalación del sujeto de Cuevas es la de la resignificación del imaginario urbano desde una mirada que da cuenta de la realidad desde abajo, desde una singularidad caída, pero atenta al movimiento de la historia recortada por la represión. La utopía es aquí solo verificable a través del tópico del viaje: "Vivan los que recorrieron el territorio/ recostados sobre la carga de un camión...El cielo era interminable,/ y desde los altos cerros un ruido/ de vientos y cuerdas remotas...Fui feliz,/ recorrí los caminos del Inca, dormí sobre el Alto La Paz, escuché los terribles lamentos .../ Echados todo el día sobre el infinito" (Adiós muchedumbres, "Los últimos días de la década del sesenta" 18). Pero el trastorno histórico borra la utopía y transforma la realidad en un retablo de pesadilla: "de pronto, se encendieron las luces, se desarmó el tablado.../ los Beatles nunca más llegaron a juntarse/ el Hombre no volvió a pisar la luna./ Empezó el Estado de Emergencia...Mis amigos no están, murieron, se extraviaron, engordaron,/ y uno que otro, que anda por ahí,/ está muy ocupado" (20).

También Juan Cameron, un poeta que se inicia en los setenta, da cuenta de la situación degradada. Autor de una serie de textos publicados en la década del 80, Perro de circo (1979), Apuntes (1981), Escrito en Valparaíso (1982), Poesía dispersa (1985), Cámara oscura (1985) y Video Clip (1989). Cameron fue uno de los poetas que buscó formas de eludir la censura para decir no diciendo y en cuyos textos aparece como trasfondo la huella brumosa de una ciudad situada. Dos textos de su libro de 1979, dan cuenta de la situación: "Donde dice amor no debe decir absolutamente nada/ basta con las manchas olvidadas por tu lecho/ Donde dice libertad léase justicia/ léase calor muslo ángel de la guarda/ líbrame de las balas locas/ Donde dice orden léase hijos de la grandísima/ pero léase en la clandestinidad" ("Fe de ratas" 31).Y en el poema "Cachorro" donde la personificación del perro sirve para representar el destino de los jóvenes: "Perdonad el pelaje descastado/ este brillo es de 
tanto restregarme/ de la baba la rabia la patada/ Perdonad el mordisco por la espalda/ es mi ternura agreste solapada/ pero ternura al fin (la única mía) / En verdad salí cachorro/ en la calle me hice perro" (30). Y en una descripción aún más directa, el sujeto también se sitúa en la pérdida: "Está bien el paraíso lo perdimos por precario/ comodato de ángel guardián era la hora/ desalojados fuimos a lanzazos a besos/mejor dicho de armas (no quiero herir a nadie).../La hora señalada se dispara en la sien/ Sólo puertas mentales se nos abren ahora" (Harris y Calderón, "La hora señalada" 32). Por su parte, Walter Hoefler, otro poeta del mismo período, también se explaya sobre el sentimiento de pérdida: "Persistir en lo que hacemos,/ reserva,/ pequeño margen/ del oficio tenazmente retenido./ Segunda expulsión del paraíso,/ agua desbordando sus lagunas./ Pequeña casa donde nadie habita" (Olivarez, "Escribir" 200). De la misma manera, elípticamente reconocible, actúa el discurso de David Turkeltaub. De su libro también de 1979, Hombrecito verde, es el poema "Informe del tiempo", que da cuenta de la situación del país y de sus habitantes, a partir de un narrador casi borrado que testimonia: "Hay una persona que ya no sirve para nada/ la taparon con diarios para esconder esta pálida vergüenza/ oh gritaron todos los periodistas/morir es una experiencia inolvidable.../ hay una gotera en el cielo/ pero el resto del país está tranquilo" (Contreras 118). Es fácil darse cuenta como en este poema y otros que hemos mencionado aparece la ciudad como simulacro. Un testimonio importante lo representa la poeta Arinda Ojeda, prisionera política que escribe desde la cárcel después de ser detenida en 1981 y recluida en Coronel. En su libro $M i$ rebeldía es vivir publicado en 1988, da cuenta de su situación personal con un estilo simple y directo, sin pretensiones y señala que "escribir es tener un espacio de libertad" (9). Su poesía es comprometida y se proyecta al futuro de una sociedad mejor, donde el amor personal y colectivo va a transformar la situación de caída y represión vigente.

Otros poetas expresan su crítica al estado de cosas de una manera casi epigramática. Es lo que hace Manuel Silva Acevedo en Palos de ciego, un poemario de 1986, que muestra una serie de textos cortos reunidos con el título de "Bajo dictadura". Por ejemplo en 2: "Se siente el latido afiebrado del país/ furúnculo sin boca" (53); 4: "Levanta el albañil/una casa en llagas./ La madre gotea leche amarga/ sobre la frente rota/de los hijos" (55); 6: "Ya se llevan a esa muchacha/ ya la quitan de la cartelera" (27). Claramente aquí aflora la representación de la ciudad sucia y apestada que se ha recogido en los textos de otros poetas y que se articula con la imagen de la ciudad como cuerpo enfermo. También Jorge Torres Ulloa, en un tono más testimonial, 
nos representa la ciudad del simulacro: "Propongo no hablar./ Regresemos al silencio./ Que no camine nadie./ Todo se detenga, / la claridad se eclipse, /al conteo de tres,/todos contengan la respiración/ hasta el máximo de sus fuerzas, / luego explotemos/ en una carcajada tremenda/ y aquí no ha pasado nada./ Absolutamente nada" (Palabras en desuso, "Ley del hielo" s/n). Y posteriormente en Graves, leves y fuera de peligro (1987), encontramos en un poema como "Promesa", dedicado a su hija de tres meses, el siguiente texto: "Vamos a conversar hija./ Yo te contaré lo que no te han contado./ Te explicaré lo que no entiendas./ Juntos leeremos La Historia, con cautela y entrelíneas./ Hoy es tiempo de mudos" (22). La voz de Torres Ulloa se irá transformando en el tiempo hasta despersonalizarse y remarcar fuertemente los significantes con una experimentación que lo acerca a la vanguardia. Por su parte, José María Memet trabaja en ese límite donde el sujeto representa con sus actos los signos mecánicos que le provoca el mundo represor: "Hoy día/ no soy yo el que escribe/ el mundo maneja mi lápiz" (Los gestos de otra vida, "Oficio" 43). A veces su poema busca la utopía en forma directa: "Canto para un presente que es el nuestro,/ canto para un sueño que es común,/canto para un pueblo enamorado.../ Mi canto es sólo la voz/ con que ustedes me enseñaron/ a vivir" (43). En otras ocasiones, su discurso se hace también denuncia al régimen militar y la enfermedad dictatorial se transmite a los cuerpos de los torturados: "Lo desnudan. La venda impide que haya rumbo/ al cual pertenecer. El labio se le rompe,/ la llaga que abre el puño se le incrusta.../ Saber que todo es tan precario: / estas palabras, por ejemplo" (Los gestos de otra vida, "El torturado" 48). En este registro más directo y combativo, más comprometido, destacan los poetas Bruno Serrano y Heddy Navarro, matrimonio que ejerce de manera tajante su militancia política y estética. Serrano escribirá en Olla común (1985) poemas directamente representativos de una lírica que quiere también ser acción directa sobre la realidad vivida: "Toesca/ no previó que La Moneda/ sería bombardeada/ se calcinarían las ventanas/ las puertas saldrían de sus goznes,/ los techos arderían como pasto seco" ("Toesca 1" 6). Lo mismo en el poema "Visita a la casa fantasma": "...tú que regresas/ del tiempo y la distancia/ con la imagen en llamas/fija en la retina/verás como brotan fantasmas / por todas las ventanas/ mientras las bombas/ caen/ y caen/ sobre la moneda" (11). A esta visión de la ciudad baldía, Heddy Navarro opone de un modo más personal una crítica situada en el patriarcalismo imperante, sin dejar de aplicar su ojo bizco sobre la situación del país y el vacío de la ciudad: "Así llegó el día en que cumplí sentencia/ se acabó la hora de visitas/Ahora caminamos sin rumbo/ el sitio de la casa está 
baldío/ las sillas y las mesas arremolinadas/ en el viento/sábanas y pañales flotan en los ríos/ Sólo quedan estos tenedores chuecos:/con ellos podemos peinar aun/ nuestros cabellos"(Contreras, "Informe 4" 217).

De los poetas mayores, Nicanor Parra es un buen ejemplo de las diferentes formas de denuncia política, directas, elípticas, mediatizadas, irónicas y paródicas, etc. En "Chistes paRra desorientar a la policia/poesía, escribe: "Si ven que torturan a alguien/háganse el de las chacras/ y si lo matan con mayor razón,/ a mí me crucificaron por sapo" (Contreras 26) o "Los civiles son gente uniformada/ también" (26). O en Poesía politica del mismo año: "Pobre fantasma de la libertad/ es un hecho que la historia se volverá a repetir/como se ha repetido tantas veces/ si los interesados no se deciden a sacarse las gafas/oscuras" (Contreras 29). Por último, un texto más irónico y descentrado es "Los cuatro sonetos del Apocalipsis" en el cual los cuatro sonetos están escritos con palabras representadas por cruces, publicado en Hojas de Parra del año 1985. Miguel Arteche edita Noches en 1976. De este libro es el poema "El joven torturado" que en su reiterada forma de letanía desarrolla la denuncia frente a la tortura: "Ahora te desnudan en la noche,/ te arrebatan la piel, la voz te llagan,/ te dejan en montón sobre las piedras, / te dividen en mil, te deshombrecen, /y te matan la luz que en ti vivía,/ y escupido en la sombra allí te dejan" (Contreras 47). En esta misma línea de denuncia, pero con la sofisticación que tiene Enrique Lihn para hacer hablar a sujetos populares que se desdoblan en el mini lugar geográfico que es el paseo Ahumada, el poema "Cámara de tortura" da cuenta de una situación similar:

Su cámara de tortura es el único hotel en que puedo ser recibido a cualquier hora/ sin previo aviso de su parte/ su orden es mi canto/ Su lapicera eléctrica es lo que hace de mi un autor copioso un maldito iluminado/ o el cojonudo que muere pollo, según quien sea yo en ese momento.../ Su metralleta es mi novia con la que tiro en sueños/ $\mathrm{Su}$ casco es el molde en el que vaciaron la cabeza de mi hijo cuando nazca/ Su retreta es mi marcha nupcial/ Su basural es mi panteón mientras no se lleven los cadáveres (Contreras 73-74).

Es indudable que Lihn desarrolla la denuncia a partir de una resignificación de la representación de la sociedad chilena y mostrando la esquizofrenia de Ahumada, Santiago y el país. La calle se convierte aquí en simulacro de la ciudad y la ciudad en simulacro del país, pero también es el cuerpo social enfermo y el baldío sucio, todas las huellas visibles del sistema dictatorial. 
Hay poetas como Ennio Moltedo que optan por una poesía elusiva y enumerativa de corte sintético y narrativo, que parece emular lo entrecortado de las comunicaciones expresivas. Un ejemplo es el poema "No puedo": "No puedo decirlo todo. Hay mensajes. Y mensajes. Palabras por el aire: susurros por las rejas; grandes paquetes y golpes; instrucciones precisas acerca del reciente comentario. Puertas y mirillas, recintos secretos -rotulados-, galerías lavadas sobre un mar impávido" (Contreras 88). En Moltedo, la censura se instala en el cuerpo y en los pensamientos del sujeto, reduciéndolo a su mínima expresión.

La representación del aislamiento y la angustia de vivir en una ciudad y un país cercados, aparece en muchos poetas de diferentes generaciones. Por ejemplo, en Delia Domínguez del libro Pido que vuelva mi ángel de 1982: "Todo está dicho: se acabaron de golpe las palabras.../ solo que vivo muda, partida en dos/ por mi alfabeto propio y mis defensas,/ pasándome, eternamente, una película donde/ no hay malos ni buenos:/ donde nadie tiene que huir" (Contreras, "Cine mudo" 86). En "Bajo sospecha", Carlos Trujillo expresa la misma idea de autocensura y separación comunicativa, aunque de otra manera: "Me encuentro constantemente bajo sospecha/ Sospecho de mí mismo/ de mi sombra/ de las calles/ de los faroles/ que no se apagan nunca.../No sé por qué / creo que estoy comenzando/ a sospechar de los jueces" (Contreras 296). Otros poetas que se inscriben en esta línea son Gregory Cohen, Carlos Cociña, Paz Molina, Jorge Montealegre y Eduardo Llanos. Un notable poema del período es "Los helicópteros" de Erick Polhammer publicado primero en la revista La Bicicleta y posteriormente en el libro Gracias por la atención dispensada de 1986. La metonimia del helicóptero con toda su carga semántica (máquina de guerra, zumbido de abejorro, panóptico y vigilancia, censura, continuidad de la represión, circularidad de la historia, etc.), logra producir un efecto político sin utilizar ningún elemento que apunte directamente a la dictadura, pero cargando cada verso con sinonimias que evocan la situación imperante en el lector activo: “...hasta que llegaron los helicópteros y los helicópteros/ se establecieron desde allí hasta siempre/ girando y zumbando como tábanos de acero los helicópteros/ girando sobre nuestros cerebros, zumbando sobre nuestros cerebros..." (Contreras 441). A la idea de la ciudad sitiada se agrega aquí la intromisión del sistema en la propia interioridad del hablante. 


\section{EN CUANTO A LA POESÍA DEL EXILIO}

En cuanto a la poesía del exilio, las primeras manifestaciones fueron de dolor, angustia, rabia, deseos de recobrar el paraíso perdido, poemas de batalla con mayor o menor carga simbólica, dependiendo de la experiencia, la madurez o la profesionalización del poeta. Los escritores se fijan al trauma histórico: los discursos son nostálgicos o recriminatorios, panfletarios y denunciatorios. Los poetas desperdigados por el mundo y sin el peso de un oficialismo represor, pueden contar libremente su visión de los hechos. Ello da margen a una profusión de formas que van desde el panfleto político del escritor improvisado hasta el esteticismo más decantado. Al comienzo es la rabia y la impotencia la que hace escribir, frente a la obligatoria salida, con textos testimoniales y exasperada denostación a los culpables. Al mismo tiempo, hay una regresión hacia la nostalgia de un pasado visto como un tiempo de plenitud, roto por el cataclismo social que ha expulsado al exiliado, junto a un sentimiento de pérdida que se vuelca en los textos sin asimilar los contextos. Al respecto, habría que señalar al menos dos elementos: 1.-Muchos poetas salieron al exilio y luego volvieron a Chile, haciendo de este un hecho circunstancial. 2.-Hay poetas que empezaron a escribir durante la dictadura en Chile y luego se exiliaron. Estas situaciones generan un movimiento de textos escritos y publicados dentro y fuera del país. Existe también un número apreciable de poetas que mantuvo su línea de trabajo estético anterior, aunque la situación política no dejó indiferente a nadie. Por otro lado, la poesía del exilio si bien tuvo ciertas variables específicas en cada lugar, determinadas por la geografía y la cultura de cada país, evidenció también la construcción de una matriz más general cuyas variables fueron establecidas por las interpelaciones de cada sociedad y la recepción que de ellas hizo cada poeta. Me explico. Es verdad que existieron poetas que vivieron el exilio con un sentimiento de pérdida aferrados a la nostalgia del país perdido, y otros cuya frustración se autorrepresentó con elementos de rabia e impotencia mezclada con una crítica exacerbada que se ha continuado reflejando en sus escritos hasta el día de hoy. Pero en forma general se podría hablar de tres etapas durante el período. La primera es la más típica, la de integración, integración al pasado, al lugar de origen y al tiempo de plenitud que aparece sobrepujado frente a la caída del momento presente. La segunda etapa es la de desintegración y fragmentación de este mundo del pasado y presenta un discurso desesperanzado hacia el presente y el futuro. Exilio es aquí sinónimo de soledad y desarraigo. Generalmente esta etapa se entremezcla 
con la primera. La tercera etapa es la de la integración cuestionada, que implica un replanteamiento de las relaciones de identidad con el entorno y el lugar de origen. Esta nueva identidad que se manifiesta en un movimiento permanente y una búsqueda de equilibrio entre las experiencias del pasado y del presente, se refleja en las obras como una articulación con el pensamiento crítico del allá. La nueva identidad se asume como un movimiento, como la maduración de una actitud creativa que sigue produciendo un arte rebelde y resistente al entrañamiento, a la enajenación y a la represión. Los escritores se distancian para leer mejor los signos de una patria que se multiplica (hay poetas que vivieron en más de un país su exilio) y que requiere nuevas formas de escritura para representarla, interpretarla, significarla.

En este contexto del exilio, hay poetas que siguen escribiendo con estrategias textuales definidas y estilo personal ya consolidado desde antes del Golpe, aunque las temáticas se relacionarán con los sucesos históricos (es el caso de Alfonso Alcalde, Armando Uribe, Efraín Barquero, Waldo Rojas, Omar Lara, Gonzalo Millán, Mahfud Massís, Humberto Díaz Casanueva o Gonzalo Rojas, entre muchos otros). Hay poetas que maduran en el exilio y desarrollan sus propias matrices escriturales a partir de un equilibrio estético que incorpora las realidades vividas (es por ejemplo el caso de Raúl Barrientos, Jorge Etcheverry, Andrés Morales, Bruno Montané, Gonzalo Santelices, Luis Mizón, Tito Valenzuela, Roberto Bolaño, etc.). Hay poetas, por último, que se inician en el exilio y al igual que en Chile, conforman procesos escriturales emergentes que se llamarán promociones de los $80 \mathrm{y}$ los 90 y que se integrarán a sus coetáneos residentes en Chile (aquí podemos citar a Patricia Jerez, Cristián Vila, Antonio Arévalo, Carmen Rodríguez, Luis Lama, Tito Alvarado o Luciano Díaz). Por último, hay una enorme gama de poetas circunstanciales que expresan sus vivencias y liberan cargas emotivas a través de una escritura especialmente apostrófica y exorcizadora. Las revistas Literatura chilena en el exilio (California 1977-1981) transformada luego en Literatura chilena, creación y crítica (California 1981-1987), así como Araucaria de Chile (Madrid 1978-1990) representarán este mismo mosaico escritural, al intentar dar cuenta de la poesía del exilio primero y en forma casi simultánea de la poesía que se escribía al interior del país, con las limitaciones obvias al comienzo seguidas por un mayor intercambio después. Más catastro que corpus, los materiales de ambas revistas, expresaron en forma fehaciente lo que se ha señalado más arriba, mostrando en sus páginas con leves diferencias, las fases por las cuales pasaron los escritores del exilio. La crítica que podría hacerse a su trabajo es fundamentalmente la prioridad 
que se le dio a los escritos de mayor compromiso político, dejando fuera en muchos casos, ya sea por limitaciones de comunicación o por prioridades de sus editores, la poesía más vanguardista que se escribía en el interior del país. Habría que indicar que si bien el dolor, la desesperación y la angustia empiezan a desaparecer con el paso del tiempo y las nuevas condiciones políticas que se dan dentro del país, esta representación de la sospecha y la censura se va a mantener por muchos años.

Alfonso Alcalde, un poeta de los cincuenta que no pudo superar el exilio y se suicidó en 1992 al retornar a Chile, escribe sobre "el último sonido que todavía escucho de Chile/ al fondo de mis 40 mil muertos" (Lara y Epple, "Golpe tercero" 33) y señala que "el mar subió en un 450\%, / el dolor en un $78,3 \%$, / la ira en un 1.234\%/...y la muerte un 5.67\% (Lara y Epple, "Golpe décimo segundo" 36). Rabia, dolor y esperanza activa priman en esta poesía que no tiene tiempo para producir una estética más estilizada: "Fuimos 40.000 veces a enterrar nuestros muertos./ Fuimos 10.000 veces a curar nuestros heridos/ y seguimos buscando los desaparecidos./ Porfía somos , raíz que estalla, somos,/ muerte reunida somos, rebeldía somos, sangre/ y huesos recogidos somos/ vida de Chile nuevo somos seremos y seguiremos siendo!” (Lara y Epple, “¿Qué crimen no cometieron?” 37). En sus escritos inéditos a su muerte, publicados en la antología Escrito en el agua de 1998, prevalece esta visión pesimista, dulcificada por un amor que no basta para suplir las carencias de la pérdida. En el "Salmo de las preguntas", el sujeto reitera el sentimiento de orfandad y penuria: "Aun andaría a la deriva sin forma/ atento a la señal más temprana/ huyendo de las prisiones invisibles. / Padre y madre de las tormentas humanas/ nunca quise nacer ¿Por qué no me escucharon?" (Nómez, Antología 250). El poeta Efraín Barquero en Francia, emulará en los Bandos marciales (1974) los bandos conminatorios de los militares, con un tono irónico, pero igualmente dolorido: "No somos gorilas/ como se ha dado en llamar a los hombres razonables./ Nos distinguimos del hermano gobierno del Brasil/ en una cosa muy importante: el clima" (Nómez, Antología, "Bando 203" 135). En el mismo tono, la ironía se vuelve parodia y desprecio en el Bando 550: "Noticias culturales. Un contingente de soldados/ está reparando el edificio, los cuadros, las estatuas/ del Museo Nacional de Bellas Artes" (134) Una visión más desgarrada cercana a la tragedia griega adopta su libro El poema negro de Chile, también de 1974, con su visión apocalíptica que muestra el término de la solidaridad familiar y colectiva: "En esta hora somos la familia diezmada/ y tú, madre, eres la sombra más espesa/ donde un niño viene a sentarse en un rincón/ con un 
gallo moribundo entre los brazos" (Barquero, "La familia diezmada", 237). Por su parte, Roberto Bolaño y Bruno Montané incluidos en la antología Chile: poesía de la resistencia y del exilio de Omar Lara y Juan Armando Epple (1978) en un poema titulado "Carta", escriben: "Todo se pone difícil./ Pasa la patrulla,/ los almacenes cierran temprano./ En la noche las farmacias/ huelen a cuartel./ Otro día/ y los niños van a la escuela/ para volver llorando/ impresionantes cadáveres/ pegados a sus ojos" (53), poema donde la ciudad baldía vuelve a reconocerse como en otros poetas. De este modo, la escritura del exilio empieza a extenderse como un gran mosaico de representaciones y de visiones que dan cuenta tanto de la censura, el terror, el miedo, la angustia y el dolor del país que queda atrás, como de la posición de los sujetos que se la imaginan o la recuerdan en la memoria. Hernán Miranda, en su poemario $L a$ Moneda y otros poemas, que obtuvo el Premio Casa de las Américas en 1974, escribirá y reiterará la idea del baldío, en un texto apostrófico: “¡La Moneda en ruinas! En rededor vi hombres y mujeres/ Contemplando inmóviles un fierro retorcido/ Una mesa quemada, trozos de espejos ennegrecidos./ Los ojos fijos, el rostro crispado./ Imagen imborrable de la herida dignidad de un pueblo" (Lara y Epple 100). Omar Lara, por su parte, escribirá en forma cronística desde Bucarest: "Del grupo de encantados que escuchábamos tus historias...ya no queda ninguno,/ estamos desperdigados. Yo en el Perú,/ de los otros no tengo noticias" (Lara y Epple, "Hablo de Luis Oyarzún, del río Valdivia, etc.” 77). Por su parte, Gonzalo Millán, primero en Costa Rica y luego en Canadá, hace también de cronista para contar la historia del "Otro" que también cuenta su historia y la sublima: "Me contó: Algunos/ compañeros crecen/ por entre las rejas/ y a la calle salen,/ de la alcantarilla/ como helechos" (Lara y Epple, "Cárcel” 92). Pero además, el cronista de los textos de Millán representa las carencias exacerbadas de la vida del exiliado en poemas donde la cotidianidad destruye al individuo y lo que lo rodea: "Más viejo que ayer/ y menos que mañana,/ a solas y en paz,/ como arroz con arvejas, / bebo mi amargo té verde" (Millán, "O "Connor St. Blues" 144). O como en el poema "Rueda de verano": Yo llevo aquí años, dice/ casi resignado,/ como una rueda (de verano)/ que gira sin avanzar/ patinando sobre el hielo" (Nómez, Chilean Literature 71). También como señala el sujeto de "La gran emigración": "Hoy hasta las ratas se van/ y nos estamos quedando solos,/ los únicos sobrevivientes/ al borde de mares estériles,/ bajo un cielo luminoso y vacío,/ longevos, grises, demasiados" (Millán 223). La experiencia de vivir en un mundo ajeno se intensifica con los conflictos familiares, y la asunción de esta problemática aparece mediatizada en algunos poemas como 
"Apocalipsis doméstico": "Un niño en un corral de palo,/ entre juguetes se desgañita llorando,/ hambriento y mojado,/ la húmeda boca abierta,/ los ojos vidriosos de lágrimas,/mirando/como la bestia de las dos espaldas/ gruñendo convulsa se revuelca/ intentando devorarse a sí misma" (Millán 118). La crónica es retomada por Armando Uribe en París, al impostar la voz de diversos testigos del crimen colectivo: "No puedo hablar y no hablo./ Ni puedo ver. No veo./ me han declarado reo./ Dicen que soy el diablo./ El asno dice: entablo/ juicio, y el buey: lo creo/ Omnipotente Deo/Chile está hecho un establo" (Lara y Epple, "Los quince testigos del crimen" 120). Otro ejemplo de este cronista-testigo, especie de sombra rulfiana que habla desde la muerte, está dado por Gonzalo Rojas exiliado en Venezuela y España: "Entonces nos colgaron de los pies, nos sacaron/ la sangre por los ojos,/ con un cuchillo/ nos fueron marcando en el lomo, yo soy el número 25.033,/ nos pidieron dulcemente ,/ casi al oído,/ que gritáramos/ viva no se quién. Lo demás/ son estas piedras que nos tapan, el viento" (Lara y Epple, "Desde abajo" 115). En mi poema "Los últimos días de Izmur" escrito durante los días del golpe, aparece la misma representación cronística de los textos anteriores, con lo cual se intenta fijar una realidad distorsionada por el discurso oficial, que la convierte en simulacro y espectáculo: "Izmur perecía y en el corazón de nosotros la impotencia crecía como una alameda/ de hojas amarillas/y a pesar de que una gran cantidad de justos había muerto manando miel y pólvora/ las azucenas no habían estallado y ningún dios se había mirado las manos con asco" (Lara y Epple 102).

Queremos terminar este sucinto recuento de la poesía del exilio con un par de ejemplos finales, tomados de los poetas exiliados en Canadá. Retomamos un libro modélico de la preocupación de los poetas del exilio por Chile, que es La ciudad de Gonzalo Millán, publicado en la ciudad de Montreal en 1979. La ciudad de Millán es la patria, pero también el espacio del exilio y la experiencia edificativa de toda realidad y de todo discurso poético. La ciudad es un poema abierto y cerrado. Cerrado porque es un discurso ficticio pronunciado por un anciano (en su versión original: en la reedición es una mujer), que a la vez es el protagonista del discurso. Abierto, porque remite a todas las otras ciudades reales o imaginarias que el ser humano se ha construido para habitar el mundo; abierto también por el tipo de discurso en montaje y la posibilidad de leer el poema al revés sin perder su sentido. Texto dentro del texto que nos aboca al problema de la re-escritura y el doble lenguaje. Compuesto de 68 fragmentos (en el original), el poema nos narra la fundación, la destrucción y la reconstrucción de la ciudad (léase 
también patria, léase mundo) real y simbólica. Personajes semialegóricos del poema son el Anciano (también el escribiente), el Enfermo, la Beldad y el Tirano. En ellos, se secreta la corrosión que encarna el poder humano y su relación con la historia personal y social del exiliado. La ciudad es, por lo tanto, un poema que alude al pasado caído y desgarrado, pero no en la forma de la nostalgia ni de la petrificación de la conciencia histórica, sino en la forma de la asunción crítica de un lenguaje que signa a la realidad para transformarla. El poema se abre "abriendo" la ciudad con su metáfora visual: "Amanece./ Se abre el poema./ Las aves abren el pico./ Cantan los gallos./ Se abren las flores./ Los oídos se abren./ La ciudad despierta/(...) La herida se abre" (Millán, Trece lunas 195). Realidad y conciencia se abren en el poema mostrando una ciudad abierta y plena que irá cambiando en el texto. Desde allí se irá desarrollando la tragedia de la ciudad destruida por el tirano, en una nueva versión de la Caída: "Desolaron el país/ Desperdiciaron el tiempo/ Desvariaron a diario/ Desalaron el mar/ desanduvieron el camino/ Destruyeron la ciudad" (231). Ciudad ahora baldía, simulacro, apestada, que pronto llega a los cuerpos y a la escritura del poema: "Vvms mrdzds/ Vvmos mrdzdos/ vivimos mordazados/ vivimos amordazados" (200), en un movimiento que parece invertirse a partir de la acción del poema sobre la realidad: "El río invierte el curso de su corriente/ El agua de las cascadas sube. / La gente empieza a caminar retrocediendo/ (...) Los muertos salen de sus tumbas/(...) Los obreros marchan cantando/ ¡Venceremos!” (256). El poema continúa estableciendo una asimilación entre el tiempo de la naturaleza y el tiempo del discurso poético: Lluvia, viento y sol son emblemas de una actividad subterránea que comienza a germinar en las profundidades de la tierra para reconstruir la ciudad diezmada. Así, el Anciano-Poeta pregona en el final: "La dictadura es reversible./ No perdurará la dictadura. Reafirmamos nuestra voluntad de lucha.../ Estos son los versos postrimeros" (280). Como ha indicado Grínor Rojo, el poeta "produce...interviniendo desde afuera, desde la vida y los trabajos del exilio, una poesía de adentro, una poesía de la patria....aun cuando no somos los pobladores visibles de la patria, seguimos construyendo en tierra ajena su ciudad" (94). Así, la ciudad de Millán reconstruida desde el exilio, es el hilván que sutura la herida, el hueco, el vacío que se suscita entre el adentro y el afuera, para hacer del poema no solo una representación de la ciudad real y simbólica del exilio y el insilio, sino también la articulación que requiere el proyecto de la ciudad futura, la que debe reconstruirse entre todos para bien o para mal, tal vez tan imperfecta como la anterior al exilio, pero siempre igualmente posible. Otro poeta que 
representó fehacientemente la escisión crítica del exilio fue Jorge Etcheverry, poeta exiliado en Canadá en donde permanece hasta hoy día. Etcheverry establece la dicotomía/integración del exilio y el insilio en dos textos publicados con algunos años de diferencia: El evasionista/ The Escape Artist en Canadá en 1981 y La calle en Chile en 1986. En estos textos se establece un vínculo entre el adentro y el afuera por varias razones. El texto canadiense es bilingüe y por lo tanto recurre a un público más amplio que el de habla hispana; da cuenta de una situación de exilio pero también remite al otro mundo de un modo difuso y lejano, aunque en ambos casos de una manera críticamente escéptica. El allá: "De las tardes pasadas en la Biblioteca Nacional leyendo las traducciones de Lautreámont en la versión de Gómez de la Serna y Pellegrini después /Hasta que el Chino Piñones le robó el libro al Mono Vélez" (El evasionista 14). O haciendo el puente histórico con el presente: "cuando con el Eric leíamos a Beckett y en una traducción que hicimos de un texto suyo traducido a su vez al inglés en la revista Poetry... Cuando llegamos por aquí, estábamos seguros que la historia ya no corría. Pasaban las semanas y los meses y siempre la misma huevá" (14). Para contrastar con una realidad actual casi anodina, en una ciudad ajena: "En mi casa, nos sentamos a la mesa todos, leemos el diario/ ...Fumamos innumerables cigarros sin filtro. Lavamos los platos y preparamos variados guisos/ Rigiendo este orden el reloj, desde la repisa de los libros...Expulsados del país, chilenos de los más diversos tipos hacen proliferar una variada anécdota a través de las ciudades de los países desarrollados o en desarrollo. ...mientras caminamos por la nieve aguachenta, estimulados o preocupados por problemas más inmediatos: zapatos pesados, la rata de inflación, la ropa que no sienta bien" (112). O como indica el sujeto en "Epitafio a la Escuela de Santiago": "una bohemia a veces, pero con muchas comodidades/ tenemos departamentos. Solemos tener televisión. Las conversaciones acerca de plata y trabajos suelen aparecer cuando tomamos cerveza... Nosotros intentamos en forma individual artimañas para escapar a la VIDA COTIDIANA/ a la que caemos otra vez como al lecho el enfermo, la vaca al pastizal" (114-116). En esta sociedad, lo que focaliza al sujeto es el conformismo frente a una situación no querida, a la que hay que adaptarse en medio de ciudades amables pero ajenas. En la otra, la reminiscencia del pasado es exultante pero se sabe borrada. Por otro lado, el libro La calle publicada en el Chile aún dictatorial del 1986, mostrará la representación que se hace el poeta del allá, a través de una multiplicidad de voces que asumen el rol de hablantes, en una ciudad sitiada, pero donde las manifestaciones de rebeldía son visibles: "Cuando 
se marchó la literatura/ con las cenizas de los últimos libros/ comenzó a florecer una palabra/ empapada de sol y sangre/ copiada al reverso de los boletos de micro/ susurrada de boca a oído en los cinematógrafos/ Mientras ellos se paseaban/ por la doble hostilidad de las calles/ con sus tijeras de cortar lenguas/ y los locutores inventaban/ un silencio hecho de palabras" ( La calle, "Permanencia de la voz" 10). Esto alude, por un lado, a la mayor comprensión que muchos poetas del exilio empiezan a tener de la situación en el interior y por otro lado, a los movimientos y cambios que se producen en los años ochenta en Chile. Se dice más que antes, se dice de otra manera y las alusiones son más directas: "Es como si la carne no fuera la carne/ $\mathrm{Ni}$ los hombres hombres/Como si la niña/ O el vendedor de frutas de la esquina/ $\mathrm{O}$ el vendedor de periódicos, por decir algo/ fueran disfraces pronto a caer/ Como si no tuvieran carne, ni huesos, ni lengua/ Como si la muerte no fuera la muerte/ Estar solo/ Tratando de amasar greda muda/ Sangrienta/ Sabiendo que afuera existen tantos, tantos" (La calle, "El torturador", 13). Es a través de la voz del otro, del torturador, del represor, del que maneja y domina el mundo de la ciudad, que Etcheverry es ahora capaz de representar ese otro mundo, el de la calle tomada y sitiada: "Entonces hacía sonar sus botas/ y se paseaba lentamente/ con la cartuchera desabrochada" (La calle, "El cerco" 12). O como en el texto "El ordenanza": "Mi mayor abriga grandes esperanzas/...Mientras tanto/ pasa las noches con la luz encendida/ viendo la televisión/ y con una botella al alcance de la mano" (La calle 18). O como en la crónica del poema "Perfección": "...se ha tenido cuidado de limpiar las calles de mendigos/ reemplazar los uniformes por trajes de civil/ llenar la Alameda de jardines/ de silencio las radios/ de espacios en blanco los periódicos" ( La calle 25). Finalmente, también Etcheverry cierra el vacío entre el exilio y el insilio. La última sección de su libro está dedicada a establecer la clausura desde algún proyecto que tiene que ver con un futuro incierto, confuso y otras generaciones. Dos poemas distintos anuncian este tiempo abierto. En "Diáspora", leemos: "Recolectores de recuerdos, paladeadotes de palabras, acarreadores de maletas y familias. Uno dice: 'Hasta aquí no más llegamos'. Y nadie comprende las palabras en los buses. Otro prepara espadas y nuevas voces, otro incuba en su cuarto la venganza. Mientras se pone al tanto de la ley de pesos y medidas, mientras graba en su mente de bronce el mapa de la ciudad. Mientras compra el alimento con extrañas monedas, intenta descifrar el lenguaje de los periódicos. Y corrige con el compás del recuerdo la ubicación de los rostros y las calles en la mesa del arquitecto de la mente" (La calle 55-56). El otro poema, con el que termina 
el libro, cierra también la brecha. Lo citamos en extenso: "Los aviones cruzarán el cielo de estas vastas ciudades/ y les diremos a los niños/ que preguntan con la mano levantada/ que van a Chile./ Mientras aprenden un castellano con acento/ que se habla entre las cuatro paredes de la casa/ y se inventa un país con geografía de sueño" (La calle, "Niños y aviones" 65).

\section{PARA FINALIZAR}

La poesía marcadamente política se siguió escribiendo hasta las postrimerías del régimen dictatorial tanto dentro como fuera del país. Lo atestiguan numerosos escritos de los cuales sería imposible dar cuenta aquí. Es cierto que en el interior de los discursos operaron transformaciones significativas desde el punto de vista de los significados y los significantes. Dejando a un lado aquellos discursos que en la medida que se abría el sistema dictatorial se hicieron más abiertamente comprometidos, con la evidente pérdida de su riqueza semiológica, las transformaciones de la confrontación política y los puentes levadizos entre el adentro y el afuera, fueron desarrollando un despliegue de nuevos discursos críticos cuyo abanico de reflexión se abrió a las distintas dimensiones del poder y el dominio social. En esta diversidad, diferentes generaciones de poetas entregarán una producción abigarrada y múltiple que a veces se confronta con las nuevas vanguardias, en la instalación que estas ejercieron al representar la imposibilidad de toda armonía y la instalación de una simbólica del deterioro, el dolor y la frustración. Fundamentalmente, esta nueva crítica política se consolida en un juicio cada vez más amplio y heterogéneo al sistema dominante y en una búsqueda de los orígenes individuales y sociales con el fin de reconstruir la memoria perdida. Es una poesía fundamentalmente histórica y ética, que busca asimilar los residuos del mundo contemporáneo para iniciar un rescate de la subjetividad, de la sociedad y de las utopías. Ya sea todavía inmersos en el testimonio individual, como es el caso de Armando Uribe, Floridor Pérez, Heddy Navarro, Bruno Serrano, Carlos Trujillo, Delia Domínguez, Stella Díaz Varín o Jorge Montealegre; ya sea como trasunto histórico de un mundo real o ficticio que se resignifica, describe o recobra, como en el caso de Raúl Barrientos, José María Memet, Sergio Mansilla, Eduardo Llanos, Alejandro Pérez, Clemente Riedemann, Carmen Berenguer, Walter Hoefler, José Angel Cuevas, Javier Campos, Jorge Etcheverry, Juan Pablo Riveros, Gonzalo Millán, entre otros; ya sea desde otra vertiente a partir de una 
mitología personal que busca revisar el archivo político anterior y desarrollar nuevas formas discursivas que a veces se cruzan con las neovanguardias: es el caso por ejemplo de la misma Carmen Berenguer, de Malú Urriola, de Juan Pablo Riveros, de Clemente Riedemann, de Sergio Mansilla, de Juan Cameron, de Manuel Silva Acevedo, de Gonzalo Millán, de Tomás Harris, de Alexis Figueroa, de Tulio Mendoza, David Miralles, Rosabetty Muñoz entre muchos poetas más jóvenes que están en esta línea. Y un alcance final: la filiación de estos poetas en la línea de la llamada "poesía comprometida o política" con sus diversos grados, no los borra de su pertenencia a otras filiaciones posibles dentro de la poesía chilena contemporánea. Muchos de ellos pueden también ser adscritos (o adscritas) a reformulaciones de género, de vanguardismos o neovanguardismos, de relaciones láricas, etnicoculturales o regionales. Resulta obvio, finalmente, que innumerables testimonios y escritos han quedado fuera de este recuento somero, que solo quiere señalar la complejidad de las perspectivas poéticas que tuvieron un énfasis político durante el período dictatorial.

\section{BIBLIOGRAFÍA}

Barquero, Efraín. Antología. Santiago: Lom Ediciones, 2000.

Bourdieu, Pierre. Las reglas del arte. Génesis y estructura del campo literario. Barcelona: Editorial Anagrama, 1995.

Calderón, Teresa, et al. Ed. Veinticinco años de poesía chilena (1970-1995). Santiago: Fondo de Cultura Económica, 1996.

Campos, Javier. La joven poesía chilena en el período 1961-1973.Minnesota-Concepción: Lar Ediciones e Institute for the Study of Ideologies and Literature, 1987.

"Lírica chilena de fin de siglo y (post)modernidad neoliberal en América Latina". Postdata 1-2 (Primer y Segundo Semestre 1998): 78-91.

Contreras, Gonzalo. Ed. Poesía chilena desclasificada (1973-1990). Vol. 1. Santiago: Étnica/ Consejo Nacional de la Cultura y las Artes, 2006.

Cuevas, José Ángel. Adiós muchedumbres. Santiago: Editorial América del Sur, 1989.

España, Aristóteles. Dawson. Santiago: Editorial Bruguera, 1985.

Etcheverry, Jorge. El evasionista/ The Escape Artist. Ottawa: Ediciones Cordillera, 1981. La calle. Santiago: Ediciones Manieristas, 1986.

"Escuela de Santiago". 33 nombres claves de la actual poesía chilena. Orfeo (1968).

Hahn, Oscar. Arte de morir. Buenos Aires: Ediciones Hispamérica, 1977. Antología virtual. Santiago: Fondo de Cultura Económica, 1996. 
Lara, Omar y Juan Armando Epple. Ed. Chile: poesía de la resistencia y el exilio. Bucarest: s.e., 1978.

Memet, José María. Los gestos de otra vida. Santiago: Editorial El Volcán, 1985.

Millán, Gonzalo. La ciudad. Montreal: Editions de la Maison Culturelle de Québec, 1979. Vida (1968-1982). Ottawa: Ediciones Cordillera, 1984. Trece lunas. Santiago: Fondo de Cultura Económica, 1997.

Moltedo, Ennio. Obra poética. Valparaíso: Ediciones del Chivato, 2005.

Nómez, Naín. Chilean Literatura in Canada/ Literatura Chilena en Canadá. Ottawa: Ediciones Cordillera, 1982.

Antología crítica de la poesía chilena. Tomo IV. Santiago: Lom Ediciones, 2006. “Transformaciones de la poesía chilena entre 1973 y 1988”. Estudios Filológicos. 42 (2007): 141-154.

"La poesía chilena: representaciones del terror y fragmentación del sujeto en los primeros años de dictadura". Acta Literaria 36 (Primer Semestre 2008): 87-101.

Ojeda, Arinda. Mi rebeldía es vivir. Colectivo de Prisioneras Políticas de Coronel, 1988.

Olivarez, Carlos, ed. Los veteranos del setenta. Antología. Santiago: Ediciones Melquíades, 1988.

Quezada, Jaime. Ed. Poesía joven de Chile. México: Siglo XXI, 1974.

Pérez, Floridor. Carta de prisionero. Concepción: Ediciones Lar, 1985.

Rojo, Grínor. Crítica del exilio. Ensayos sobre literatura latinoamericana actual. Santiago: Pehuén Editores, 1987.

Serrano, Bruno. Olla común. Santiago: Ediciones Tragaluz, 1985.

Silva Acevedo, Manuel. Palos de ciego. Concepción: Ediciones Lar, 1986.

Torres Ulloa, Jorge. Palabras en desuso. Edición particular, 1978.

Graves, leves, fuera de peligro. Concepción: Ediciones Lar, 1987.

Turkeltaub, David. Ed. Ganímedes 6. Santiago: Editorial Ganímedes, 1980.

White, Steven. Ed. Poets of Chile. A Bilingual Anthology 1965-1985. Breensboro: Unicorn Press, 1986.

Literatura Chilena en el exilio (California 1977-1981) y Literatura Chilena, creación y crítica (California, 1981-1987).

Araucaria de Chile (Madrid, 1978-1990). 
